\title{
Ultra-low coupling loss fully-etched apodized grating coupler with bonded metal mirror
}

\author{
Ding, Yunhong; Peucheret, Christophe; Ou, Haiyan
}

Published in:

IEEE International Conference on Group Four Photonics

Link to article, DOI:

10.1109/Group4.2014.6961965

Publication date:

2014

Document Version

Publisher's PDF, also known as Version of record

Link back to DTU Orbit

Citation (APA):

Ding, Y., Peucheret, C., \& Ou, H. (2014). Ultra-low coupling loss fully-etched apodized grating coupler with bonded metal mirror. In IEEE International Conference on Group Four Photonics (pp. 139-140). IEEE. https://doi.org/10.1109/Group4.2014.6961965

\section{General rights}

Copyright and moral rights for the publications made accessible in the public portal are retained by the authors and/or other copyright owners and it is a condition of accessing publications that users recognise and abide by the legal requirements associated with these rights.

- Users may download and print one copy of any publication from the public portal for the purpose of private study or research.

- You may not further distribute the material or use it for any profit-making activity or commercial gain

- You may freely distribute the URL identifying the publication in the public portal 


\title{
Ultra-low coupling loss fully-etched apodized grating coupler with bonded metal mirror
}

\author{
Yunhong Ding ${ }^{*}$, Christophe Peucheret ${ }^{* \dagger}$, and Haiyan $\mathrm{Ou}^{*}$ \\ *Department of Photonics Engineering, \\ Technical University of Denmark, 2800 Kgs. Lyngby, Denmark \\ Email:yudin@fotonik.dtu.dk \\ 'University of Rennes 1 - ENSSAT, \\ FOTON Laboratory - CNRS UMR 6082, 22300 Lannion, France
}

\begin{abstract}
A fully etched apodized grating coupler with bonded metal mirror is designed and demonstrated on the silicon-on-insulator platform, showing an ultra-low coupling loss of only $1.25 \mathrm{~dB}$ with $3 \mathrm{~dB}$ bandwidth of $69 \mathrm{~nm}$.
\end{abstract}

\section{INTRODUCTION}

Efficiently coupling light between standard single mode fibers (SSMFs) and nano-waveguides has been one of the most challenging problems for photonic integrated circuits. The use of grating couplers is one of the most efficient means to overcome this difficulty. By properly designing the scattering strength and period of the scattering units, light can be efficiently output at a specific angle from the normal to the circuit and directly coupled to an SSMF with high efficiency. The biggest advantage of grating couplers is that neither chip cleaving nor lensed fibers are required, making wafer-scale testing possible. Traditional shallowly etched uniform grating couplers $[1,2]$ have the drawback that extra fabrication steps are required and the coupling efficiency is sensitive to the etching depth. In addition, two factors limit the coupling efficiency of this type of grating. One is the loss due to power leakage to the substrate. It can be reduced by introducing a metal mirror $[3,4]$ beneath the grating area. However, one cannot overcome the second type of loss due to the intrinsic mode mismatch between the exponentially decaying field profile of light diffracted from those uniform gratings and the Gaussian-like field profiles of SSMFs. In order to simplify the fabrication process, as well as to achieve low coupling loss, a fully etched apodized grating coupler is preferred. A number of fully etched grating coupler designs have been reported $[5,6]$. However, their coupling efficiency is still limited, either by the mode mismatch or by power leakage to the substrate.

Previously, we have proposed and demonstrated an apodized etched grating coupler based on fully etched photonic crystals (PhCs) with air as upper cladding [7]. Based on the same design method, we design and demonstrate a fully-etched apodized grating coupler using $\mathrm{PhCs}$ on the silicon-on-insulator (SOI) platform with $\mathrm{SiO}_{2}$ as upper cladding and with a bonded mirror. Thanks to both apodizing the grating coupler and the bonded mirror, both mode mismatch and power leakage loss are minimized, resulting in an ultra-low coupling loss of $1.25 \mathrm{~dB}$, which is, to the best of our knowledge, the lowest coupling loss ever reported for fully etched grating couplers.

\section{DESIGN AND OPTIMIZATION}

The proposed grating coupler is schematically depicted in Fig. 1. Its design is based on flip-chip bonding of a silica-clad fully etched silicon $\mathrm{PhC}$ grating coupler on a silicon carrier wafer. The thickness of the top silicon device layer is $250 \mathrm{~nm}$. Along the grating, an artificial material is introduced for the scattering units with refractive index $n_{i}$ changed, and length of scattering unit $l_{i}$ is also changed. $\mathrm{SiO}_{2}$ is used as upper and lower cladding material with thicknesses of $h_{u}$ and $h_{d}$, respectively. A metal mirror is introduced below the lower cladding and is bonded to the silicon carrier wafer.

The coupling angle $\theta$ is designed to be $15^{\circ}$. The mirror metal is titanium (Ti) with thickness of $100 \mathrm{~nm}$. In the design, the artificial material slot width is fixed to be $345 \mathrm{~nm}$, and the scattering strength is tuned by changing $n_{i}$ and $l_{i}$. The distributions of $n_{i}$ and $l_{i}$ of the grating coupler are designed as shown in Fig. 2(a). The detailed design method can be found in [7]. The lower cladding thickness $h_{d}$ plays an important role on the coupling efficiency. Fig. 2(b) shows the coupling efficiency of the transverse electric (TE) mode as a function of $h_{d}$ calculated by two-dimensional (2D) eigenmode expansion method (EME) with $h_{u}$ set to $1 \mu \mathrm{m}$. One can find that the coupling efficiency depends periodically on $h_{d}$, and reaches a maximum at $h_{d}=1600 \mathrm{~nm}$. With $h_{d}=1600 \mathrm{~nm}$, the coupling efficiency is further calculated as a function of wavelength, as shown in Fig. 2(c). A peak coupling efficiency of $81 \%$ (corresponding to $0.91 \mathrm{~dB}$ coupling loss) is predicted at $1560 \mathrm{~nm}$ with a $3 \mathrm{~dB}$ bandwidth of $74 \mathrm{~nm}$. The

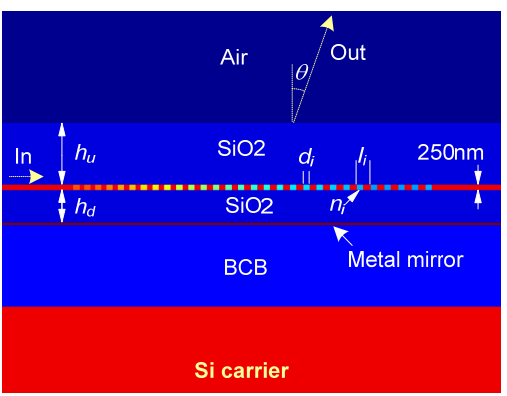

Fig. 1. Schematic structure of the proposed grating coupler. 

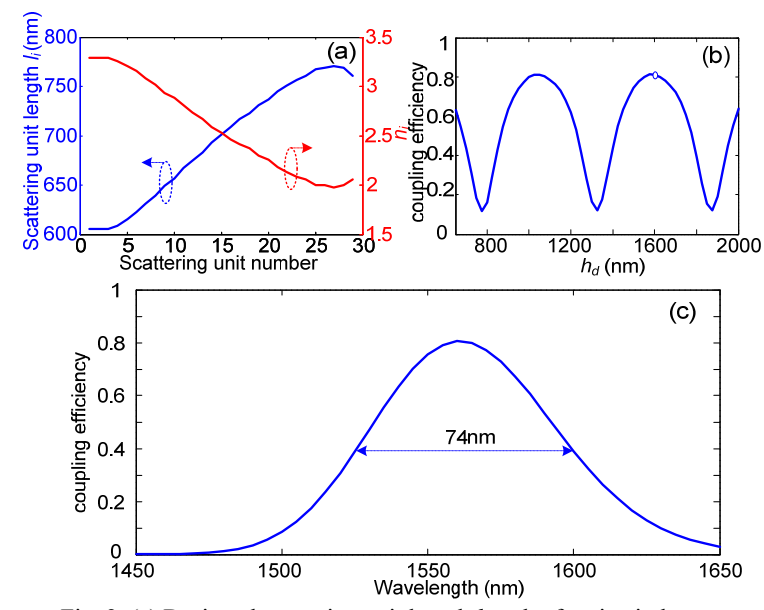

Fig. 2. (a) Designed scattering unit length $l_{i}$ and refractive index $n_{i}$ distributions of the grating coupler. (b) Simulated coupling efficiency as a function of lower cladding thickness. (c) Simulated coupling efficiency as a function of wavelength with $h_{d}=1.6 \mu \mathrm{m}$ and $h_{u}=1 \mu \mathrm{m}$.

artificial material slots are then replaced by a photonic crystal with triangular lattice [7], and the hole-diameters are calculated by the effective index approximation method.

\section{DEVICE FABRICATION AND CHARACTERIZATION}

The device was designed and fabricated on a commercial SOI sample with top silicon thickness of $250 \mathrm{~nm}$ and buried silicon dioxide (BOX) of $3 \mu \mathrm{m}$. Fig. 3 shows the fabrication process. A single step of standard SOI processing, including e-beam lithography and inductively coupled plasma (ICP) etching was first used to fabricate the grating coupler and silicon nano-waveguide simultaneously (see Fig. 3(a)). A $1600 \mathrm{~nm}$ thick layer of $\mathrm{SiO}_{2}$ was then deposited on top of the grating coupler (see Fig. 3(b)), followed by deposition of $100 \mathrm{~nm} \mathrm{Ti} \mathrm{(see} \mathrm{Fig.} \mathrm{3(c)).} \mathrm{Afterwards,} \mathrm{about} 2 \mu \mathrm{m}$ benzocyclobutene (BCB) was spined on both the sample and silicon carrier wafer (see Fig. 3(d)). The sample was then flip-bonded on the silicon carrier wafer (see Fig. 3(e)) and thermally cured in a BCB oven. Finally the substrate of the chip was removed by ICP fast etching (see Fig. 3(f)). Fig. 4(a) and 4(b) show details of the fabricated device. In order to test the coupling loss, two identical grating couplers were fabricated with a $700 \mu \mathrm{m}$ long single-mode straight waveguide introduced in between. The waveguide width was tapered from $12 \mu \mathrm{m}$ for the grating couplers to $450 \mathrm{~nm}$ for the single mode straight waveguide with $500 \mu \mathrm{m}$ tapering length. The propagation loss of the single mode silicon (a)

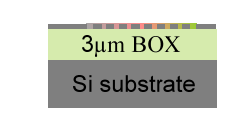

(d)
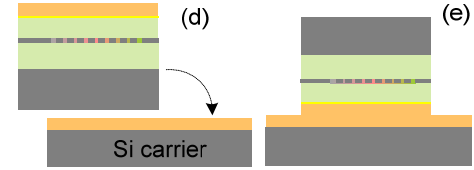

(e)

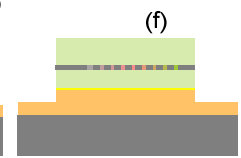

Fig. 3. Fabrication process of the grating coupler with bonded mirror. (a) Grating coupler fabrication based on standard e-beam lithography and ICP etching. (b) $\mathrm{SiO}_{2}$ deposition. (c) Metallic mirror deposition. (d) BCB spinning for both sample and carrier wafer. (e) Bonding. (f) Si substrate removal. waveguide was measured to be $4 \mathrm{~dB} / \mathrm{cm}$. The fiber-to-fiber transmission was measured, and the coupling loss was calculated as half of the fiber-to-fiber transmission minus the propagation loss in the straight wave- guide. An ultra-low coupling loss of $1.25 \mathrm{~dB}$ (corresponding to $74 \%$ coupling efficiency) was obtained at $1560 \mathrm{~nm}$ with a $3 \mathrm{~dB}$ coupling bandwidth of $69 \mathrm{~nm}$, as shown in Fig. 4(c), in good agreement with the numerical predictions. In order to test the fabrication tolerance, the size of the holes was increased by $d_{\text {hole }} 8 \mathrm{~nm}$, resulting in a peak coupling wavelength shift of $20 \mathrm{~nm}$ without peak coupling efficiency degradation. To the best of our knowledge, this is the lowest coupling loss ever reported for fully etched grating couplers.

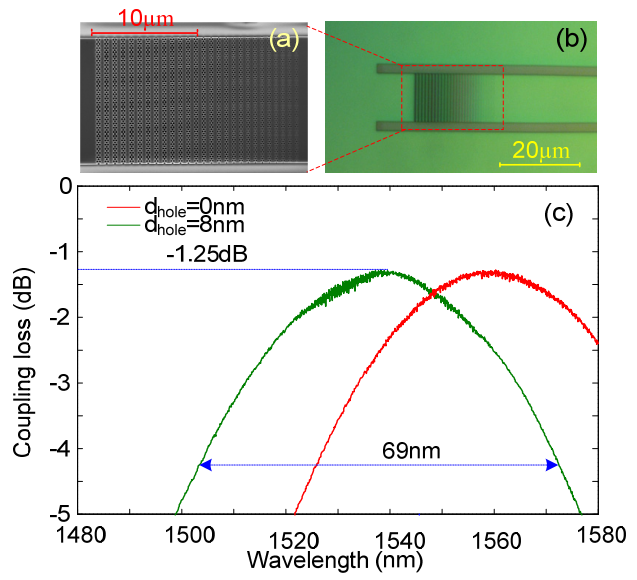

Fig. 4. (a) Scanning electron microscopy (SEM) image and (b) optical microscopy image of the fabricated grating coupler. (c) Measured coupling loss of the fabricated coupler with and without hole size change.

\section{CONCLUSION}

We have designed and demonstrated a fully etched apodized grating coupler using PhCs with bonded mirror. A record low coupling loss of only $1.25 \mathrm{~dB}$ was measured with $3 \mathrm{~dB}$ coupling bandwidth of $69 \mathrm{~nm}$.

\section{ACKNOWLEDGEMENT}

This work is supported by the Danish Council for Independent Research (project 1337-00152).

\section{REFERENCES}

[1] T. Tamir and S. T. Peng, "Analysis and design of grating couplers," Appl. Phys., vol. 14, pp. 235-254, 1977.

[2] D. Taillaert, et al. , "An out-of-plane grating coupler for efficient butt-coupling between compact planar waveguides and single-mode fibers,” IEEE J. Quantum Electron., vol. 38, pp. 949-955, 2002.

[3] R. Halir, et al., "Continuously apodized fiber-to-chip-surface coupler with refractive index engineered subwavelength structure," Opt. Lett., vol. 35, pp. 3243-3245, 2010.

[4] L. Liu, et al., "High-efficiency, large-bandwidth silicon-on-insulator grating coupler based on a fully-etched photonic crystal structure," Appl. Phys. Lett., vol. 96, pp. 051126, 2010.

[5] F. V. Laere, et al., "Compact grating couplers between optical fibers and silicon-on-insulator photonic wire waveguides with $69 \%$ coupling efficiency," in OFC'2006, U.S., paper PDP15.

[6] W. S. Zaoui, et al., "Bridging the gap between optical fibers and silicon photonic integrated circuits," Opt. Express, vol. 22, pp. 1277-1286 (2014).

[7] Y. Ding, et al., "Ultra-high-efficiency apodized grating coupler using fully etched photonic crystals," Opt. Lett., vol. 38, pp. 2732-2734, 2013. 